\title{
Facebook Brand Communities and Social Capital
}

\author{
By Hyunjin Seo * \\ Ren-Whei Harn \\ Salman Husain
}

\begin{abstract}
This study examines the role of social media-based marketing in generating social capital by analyzing wall posts and comments on Facebook pages of a for-profit social enterprise (TOMS) and a conventional for-profit company (Sperry Top-Sider). Our content analysis shows that compared to the Sperry Facebook page, the TOMS Facebook page featured a higher proportion of wall posts involving community engagement and social issues. While aspects of bonding social capital were most prominent in both Facebook pages, the TOMS online community was more likely to generate bridging social capital than the Sperry online community. These results suggest that the social entrepreneurship aspect of TOMS contributes to information exchanges between weak ties and forging of new ties via its brand community on Facebook. This research enhances our understanding of differences and similarities between for-profit social enterprises and conventional for-profit companies in use of social media for public relations and their implications for creating a dialogic space essential for facilitating development of social capital.
\end{abstract}

Keywords: brand community, marketing, Facebook, social capital, social enterprise

\section{Introduction}

With the wide availability and affordability of digital communication technologies, social relationships have increasingly been formed and maintained by popular social networking platforms such as Facebook and Twitter (Anderson \& Caumont, 2014; Pew Research Center, 2015). People of different ages use various types of social media to connect with friends and family in and outside of their country and to get news and information on diverse issues. A Pew Research Center report shows that more than $70 \%$ of US adult Internet users participated in online social networking as of 2014 (Pew Research Center, 2015). Worldwide, there are about 1.3 billion active users of Facebook and 270 million users of Twitter (Ross, 2014; Somaiya, 2014; Twitter, 2014).

As more and more social interactions take place online, studies have examined their implications for society with particular interest in consequences for development of social capital (e.g., Ellison, Vitak, Gray, \& Lampe, 2014; Gil de Zúñiga, Jung, \& Valenzuela, 2012). Social capital, a concept that has long been studied in different fields, generally refers to latent resources embedded in social networks that facilitate individuals' or groups' social actions to create public goods or social benefits for those involved in the interactions and potentially beyond

\footnotetext{
* Associate Professor \& Docking Faculty Scholar, Faculty Affiliate at KU Information and Telecommunication Technology Center, School of Journalism and Mass Communications, University of Kansas, USA.

${ }^{\dagger}$ PhD Student, School of Journalism and Mass Communications, University of Kansas, USA.

* Program Associate, Syria Relief and Development, USA.
} 
those immediate groups (Bourdieu, 1986; Coleman, 1988; Ellison et al., 2014). Scholars have investigated how social relationships forged, maintained, or supported via social networking sites help generate different levels and types of social capital (Ansari, Munir, \& Gregg, 2012; Ellison et al., 2014; Mano, 2014).

The increased interest in the role of social media in social capital is also resonant in the field of marketing. This is in line with calls for more research examining how public relations might help generate social capital and thus address social problems (Kennan \& Hazelton, 2006; Sommerfeldt \& Taylor, 2011; Taylor, 2011). Indeed, previous research showed that brand communities are an important form of social network through which consumers create and benefit from social capital (Habibi, Laroche, \& Richard, 2014).

An area of research that has been rarely addressed in this field is how marketing in social entrepreneurship might contribute to generating or enhancing social capital. While characteristics of social enterprises vary, they generally refer to entities that apply commercial strategies to address important social problems (Mikami, 2014; Teasdale, Lyon \& Baldock, 2013). More empirical research in this area is needed, given the increasing number of social entrepreneurial projects in recent years (Skoll World Forum, 2013; Trumbull, 2014). This notion of combining a non-profit sector mission with a for-profit business model—such as TOMS' buy one and give one model - has increasingly captured the imagination of business people and citizens seeking to identify financially sustainable ways of dealing with issues such as poverty, disease, and violence. However, research on social entrepreneurship has been lacking, in particular in the context of marketing and social capital (Gedajlovic, Honig, Moore, Payne, \& Wright, 2013).

Against this backdrop, this study examines whether and how a for-profit social enterprise differs from a conventional for-profit company in terms of using social media for public relations. We further investigate whether a for-profit social enterprise's social media-based marketing is more likely to create social capital, compared with a conventional for-profit company. To empirically analyze these issues, we conduct a content analysis of Facebook posts by TOMS (an example of a for-profit social enterprise) and Sperry Top-Sider (an example of conventional for-profit company) and compare and contrast their public relations on Facebook and implications for social capital. The two companies sell similar products aimed at similar target audiences (i.e., millennials), but their missions are different in that TOMS' business model is supposedly designed, in part, to address social problems such as children's health and education (Ellett, 2014; Mintel, 2014a, 2014b).

Our results will help us understand whether and how social media helps social entrepreneurs create a dialogic space that is essential for facilitating social capital and community inquiry. This research also contributes to enhancing our understanding of differences and similarities of for-profit social enterprises and conventional for-profit companies in terms of using social media for marketing and their implications for generating social capital. Finally, the current study helps advance theoretical and methodological frameworks in studying the role of social media-facilitated marketing for addressing social problems at the local, national, or international level. 


\section{Previous Research}

\section{Social Media and Social Capital}

As social capital has been studied in many different fields, the concept has generated various, and sometimes inconsistent, definitions and measurements. This led some scholars to argue that there exist "gaps in treatment, method, and theoretical development" in social capital-related research (Kennan \& Hazelton, 2006, p. 321). However, there are several common dimensions or aspects that transverse most research studies in social capital. First, social capital is generally defined in terms of resources stemming from social networks and expectations or outcomes of benefitting those involved in the interactions and potentially beyond those immediate groups (Coleman, 1998; Putnam, 2000; Ellison et al., 2014). For example, Coleman (1998) focused on resources that can aid social action for desirable social benefits in explicating the concept of social capital, and identified three forms of social capital: "obligation and expectations," "information-flow capability," and "norms" (p.119). In comparison, Putnam (2000) defined social capital as connections among individuals and the norms of reciprocity and trustworthiness that result from those connections. In this study, we use the term social capital to refer to latent resources embedded in social networks that facilitate individuals' or groups' social actions to create social benefits (Bourdieu, 1986; Coleman, 1988; Ellison et al., 2014).

One of the most widely used dimensions of social capital is bonding $v s$. bridging social capital. Bonding social capital is generated from strong or core ties such as family members or close friends who are likely to share norms and trust (Ansari, et al., 2012; Lin, 2001; Putnam, 2000). In comparison, bridging social capital tends to stem from weak or peripheral ties such as causal acquaintances that can offer unique or novel information or resources. Lin (2001) argued that bonding social capital is built from "close relations inside of cohesive groups" and bridging social capital is generated between groups.

Another dimension of social capital that has been studied in the context of social media is type of resource mobilization (Ellison et al., 2013). This is because social media has been considered as an important platform for information seeking and making requests; online social networks are often in tandem with offline relationships and cover both strong and weak ties (Ellison et al., 2013; Lampe, Ellison, \& Steinfield, 2006; Morris, Teevan, \& Panovich, 2010). Ellison et al. (2013) developed a coding scheme to differentiate mobilization requests on Facebook. The dimensions they developed include: (i) recommendation and social connection, (ii) factual knowledge, (iii) social coordination, invitation, and offer, (iv) favor, request, collective action, and (v) opinion/poll. These items were categorized by the amount of effort needed to fulfill the request and typewhether it is opinion, information or social coordination.

Previous research found that different types of social networking services or user behavior could lead to different types of social capital. For example, Aubrey and Rill's (2013) survey of undergraduate students showed that habitual use of Facebook is associated with "gains in online bridging and offline network capital" 
(p. 479). Similarly, other studies argued that participation in Facebook groups facilitate civic engagement (Johnson, Zhang, Bichard, \& Seltzer, 2010; Zhang, Johnson, Seltzer, \& Bichard, 2010). Johnson et al.'s (2010) study found that "the connective and interactive affordances" of social network services made people more likely to be part of civic participation. In addition, using multiple media channels, instead of one type of "old or new media," was shown to contribute to bridging and bonding social capital (Doerfel \& Haseki, 2013).

Given the increasing availability and affordability of social networking services, it is important to further investigate how changes in this new communication environment may influence formation and utilization of social capital. Our study examines this topic while focusing on the effects of social media-based public relations on social capital. Now we turn our discussion to the context of public relations and social capital in the age of digital media and online social networking.

\section{Marketing and Social Capital in the Social Media Age}

The emergence of information and communication technologies (ICTs) has influenced the ways organizations interact with their target audiences. In particular, widely available social networking services such as Facebook and Twitter have enabled organizations to directly engage their target audiences without having to go through traditional intermediaries such as mass media (Benkler, 2006; Zarhana, Arsenault, \& Fisher, 2013). This disintermediation, fueled by the prevalence of digital devices, has opened up a lot of possibilities and challenges for organizations' relationship building and management with publics.

As digital media has become an integral component of many organizations' communication with publics, studies have examined how different relationship dimensions are supported in the digital media age. In their study of Fortune 500 websites, $\mathrm{Ki}$ and Hon (2006) found that openness and access are the most commonly used relationship cultivation strategies in the companies' websites. Similarly, Kelleher and Miller's study (2006) showed that conversational human voice and communicating relational commitment led to more positive relationship outcomes.

The implications of digital media for organizations' relationships with publics can be applied to social capital. Indeed, the role of public relations in improving communities has been an important topic in the public relations scholarship (Kruckeberg \& Stark, 1998; Leeper, 2000; Heath, 2006; Taylor, 2011). For example, in his argument for a "fully functioning society," Heath (2006) suggests that public relations can contribute to generating social capital by enacting organizational rhetoric which he considered to be part of the "collective advocacy." Taylor (2011) adopted this notion of "a fully functioning society" in examining how rhetoric and public relations-facilitated communication helps create social capital in a town in Jordan. Based on her case study, she argued that rhetoric and public relations could produce different types of social capital necessary for building and sustainment of a community or society. 
Brand communities created by companies on popular social networking sites are particularly relevant for our research on social media-facilitated public relations in social capital. Muniz and O'Guinn (2001) defined brand community as a "specialized, non-geographically bound community, based on a structured set of social relations among admirers of a brand" (p. 412). The brand community provides a venue for an organization to share news and information about the brand and for consumers to express admiration or voice concerns about the brand (Habibi et al., 2014; Muniz \& O’Guinn, 2001). Digital communication technologies facilitate interactivity within the brand community. Based on their qualitative analysis of brand communities on social media, Habibi et al. (2014) identified shared consciousness, impressions management, and community engagement as practices prominent in brand communities online. Shared consciousness is generally associated with a sense of belonging to the brand community such as experiences as "being in a family" (Habibi et al., 2014, p. 126). Impression management is mainly about making consumers feel good about consuming the brand by sharing positive news about the brand. Finally, community engagement refers to a set of practices where customers are encouraged to share their experiences and stories related to the brand.

Facebook has emerged as an important platform for brand communities. As mentioned above, Facebook is the most popular social media site as of 2014 with about 1.3 billion active users worldwide (Pew Research Center, 2015; Somaiya, 2014). Companies have created their own page on Facebook to engage potential consumers and publics in general. For example, TOMS' Facebook page is an important channel for facilitating its brand community, and a lot of interactions take place between the company and its consumers and among consumers on the Facebook page. In the next section, we provide an overview of two companies that we analyze in this study-TOMS, a for-profit social enterprise, and Sperry TopSider, a conventional for-profit company_and their Facebook communities.

\section{Facebook Brand Communities of TOMS and Sperry Top-Sider}

Blake Mycoskie founded TOMS in 2006 after he visited a village in Argentina and realized local children did not possess shoes to protect their feet. TOMS is built upon the One for One model-donating one pair of shoes for every pair sold. This model does not just apply to shoes; in 2011, the product line expanded to eyewear as well (Ellett, 2014). For every eyewear sold, TOMS promises to restore sight for one person in need. Most recently, they have expanded their product line to include coffee to provide clean water in developing countries (Strom, 2014). TOMS chief digital officer Zita Cassizzi states that TOMS is not just a company focused on marketing various products but a company driven by a social movement (Ellett, 2014). Therefore, TOMS' stated goal in customer interaction is not simply on selling a product but to engage them to join a movement. TOMS reached a benchmark of giving away 10 million pairs of shoes in 2010, just four years after its founding.

TOMS appeals to "socially minded millennials" and consumers who support causes like giving shoes to children in need, buying shoes made from sustainable 
and vegan materials, or animal conservation initiatives (Mintel, 2014a). Reports show that when it comes to purchase decisions, millennials value experiences that "makes them feel good about themselves, receives positive online reviews, helps them stand out, or is based on a recommendation from others" (Mintel, 2014b, p. 3 ). Specifically, millennials who are dads are much more likely to make purchases from companies demonstrating corporate altruism (Mintel 2014b). Another relevant fact for our research is that millennials are less wary than other adults in sharing information and opinions with marketers online.

However, TOMS has also come under criticism by some researchers and pundits (e.g., Poulos, 2012; Wydick, Katz \& Janet, 2014). Wydick et al.'s (2014) experimental study in El Salvador examining the influence of TOMS donations of children's shoes on local shoe markets suggests that future shoe purchases at a local shoe store were slightly lower among households receiving donated shoes from TOMS. Others pointed out that the TOMS model does little to actually solve a social problem (Poulos, 2012).

TOMS utilizes multiple social media platforms including Facebook, Twitter, Instagram, Pinterest, Google Plus, Tumblr, and YouTube. TOMS' main Facebook page had about 2.8 million as of December 2014. Our analysis shows that the TOMS Facebook page receives a high level of audience reactions with its wall posts receiving an average of 1,500 likes and 36 comments. Through its social media platforms, TOMS features new products and corporate altruism messages as well as behind-the-scenes accounts of specials events.

Sperry Top-Sider (Sperry) is a company that we compare with TOMS, as the two sell similar products and appeal to similar target audiences (i.e., millennials). Sperry is a subsidiary of Collective Shares, Inc., which is a subsidiary of the overall company Wolverine World Wide Inc (Sperry Top-Sider, 2014). Sperry is also a non-athletic footwear brand and specializes in casual footwear. Sperry markets its brand as "a way of life," suggesting that its products are integral in the daily lives and activities of its customers.

Social media is an important platform for Sperry to engage its target audience. The company has a presence on major social media sites such as Facebook, Twitter, Instagram, YouTube, and Pinterest. Sperry's Facebook page had about 1.1 million fans as of December 2014. On average, Sperry's Facebook wall post receives 900 likes and 17 comments. It also has a number of social media campaigns aimed at getting the consumer involved as a member of the Sperry brand. For example, the hashtag, \#topsiding, allows consumers to share photos on Twitter and Instagram to express the state of mind or "what you do and how you feel" when wearing Sperry footwear. Overall, the social media presence is anchored in storytelling and forging personal connections with consumers.

Our review of the literature suggests that social media might be able to help create a dialogic space essential for facilitating development of social capital. However, little empirical research has examined how social media use by different types of businesses might result in generating different types of social capital. The current study attempts to fill this gap by examining this issue in the context of a for-profit social enterprise $v s$. a conventional for-profit company. We propose the following research questions. 


\section{Research Questions}

- RQ1: How do the TOMS Facebook page and the Sperry Top-Sider Facebook page differ in terms of wall post topic and brand community type?

- RQ2: How do the TOMS Facebook page and the Sperry Top-Sider Facebook page differ in terms of social capital generated through the Facebook page?

- RQ3: What are the characteristics of Facebook posts that generated most audience reactions?

\section{Methods}

We conducted a content analysis of wall posts and audience reactions to those wall posts on the official Facebook pages of TOMS and Sperry Top-Sider (Sperry) from October 1, 2013 to September 30, 2014. Content analysis is an appropriate research method as the current study is aimed at understanding what types of comments the companies and their fans generate on Facebook (Krippendorff, 2013). In selecting our sample, we used a systematic random sampling approach of choosing every third wall post on each Facebook page during the analysis period. This resulted in 163 wall posts and 5,952 comments on the TOMS Facebook page and 91 wall posts and 1,618 comments on the Sperry Facebook page. We analyzed wall post type, brand community type, and audience comment type along with types of social capital generated through the Facebook pages.

Coding Scheme. Previous studies on public relations, brand communities, and social capital guided development of coding categories (e.g., Ansari et al., 2012; Ellison et al., 2013; Habibi et al., 2014). We combined it with a constant comparative method in which the wall posts and comments were examined by two coders for potential use of categories developed in previous studies and creation of new categories. These resulted in the following categories for coding wall posts and comments on the two Facebook pages. The categories for coding the most prominent wall post topic included: (i) product promotion, (ii) event promotion, (iii) customer service, (iv) social issue promotion, and (v) other. The product promotion category was used for wall posts that were mainly aimed at promoting the company's products, while the event promotion category covered wall posts that publicized events organized by the company. The customer service category covered wall posts aimed at providing service before, during, or after a consumer's purchase of their product. The social issue promotion category covered wall posts designed to advocate a social cause or address a social issue.

We also analyzed the most prominent brand community type in each wall post. Based on previous research on social media-based brand communities (Habibi et al., 2014), we used the following categories: (i) shared consciousness, (ii) impressions management, (iii) community engagement, (iv) other, and (v) none. The shared consciousness category covered posts manifesting "a feeling of being in a family or a close network of friends" such as talking about their 
experiences as "TOMS family" (Habibi et al., 2014, p. 126). The impressions management category was used for wall posts that share "good news about the brand and justifying the consumption of the brand" (Habibi et al., 2014, p. 128). The community engagement category was for wall posts featuring call to action or encouraging customers to share their experiences and stories related to the brand.

In coding types of social capital generated on these Facebook pages, we analyzed an entire conversation thread - a wall post and comments under the wall post. Two analysis dimensions were used for this: bonding vs. bridging and resource mobilization. For the first dimension, we coded whether the type of social capital was (i) bonding, (ii) bridging, or (iii) none. The conversation thread was coded bonding if it indicated interactions between close social networks such as exchange of knowledge, trends, ideas, news or opinions and "bringing together individuals for shared events or group solidarity" (Ansari et al., 2012; Burt, 2001; Williams, 2006). In comparison, bridging was coded if social capital in the conversation thread showed forging new relationships or interactions between weak social ties.

For the second dimension of social capital, we analyzed a resource mobilization aspect - whether and how Facebook posts were used to mobilize resources (Ellison et al., 2013). The categories used for this dimension were: (i) recommendations and social connection, (ii) factual knowledge acquisition, (iii) social coordination, invitation, or offer, (iv) favor and request, (v) opinion/poll, (vi) other, and (vii) none. The category of recommendations and social connection covered a conversation thread where a request for a suggestion or referral is mentioned. The factual knowledge acquisition category covered a conversation thread that includes "a question that assumes or expects a correct answer" (Ellison et al., 2013, p.158). The category of social coordination, invitation, or offer was for a conversation thread that indicates "a search for others with similar agencies or motives or for company (an invitation) with an assumed goal of collaboration or meeting" (Ellison et al., 2013, p. 158). The favor and request category covered "a request for help or action from one's network for any number of things, including physical assistance, needed items, or emotional support" (Ellison et al., 2013, p. 158). Lastly, the opinion/poll category covered "a request for an opinion to be given in reaction/response to a status update; a vote or a choice between two alternatives to be made; or a general solicitation of what people are doing" (Ellison et al., 2013, p. 158).

In analyzing comments for each wall post, we first coded numbers of comments posted by the company and by other Facebook users such as Facebook fans. We also analyzed numbers of comments on product/brand inquiry (comments asking about the brand or its products), product evaluation (comments offering evaluations of the brand or its products), event inquiry (comments asking about an event related to the brand), event evaluation (comments offering evaluations of an event related to the brand), service inquiry (comments asking about the brand's customer service), service evaluation (offering evaluations of the brand's customer service), social contribution inquiry (comments asking about the brand's contribution to society or community), and social contribution evaluation 
(comments offering evaluations of the brand's contribution to society or community).

Other items coded in analyzing comments include valence (whether the post was positive, neutral, or negative) and language type (whether the comment was in English or not). Total numbers of likes, comments, and shares for each wall post were also coded.

Inter-coder Reliability. For an inter-coder reliability test, two trained coders coded the same $10 \%$ of the sample wall posts and comments from each Facebook page (Krippendorff, 2013; Riffe, Lacy, \& Fico, 2005). Inter-coder reliability was determined using Scott's pi. The inter-coder reliability score for wall post topic, brand community type, and comment topic was $0.92,0.91$, and 0.93 , respectively. The inter-coder reliability score for bonding $v s$. bridging social capital type and resource mobilization social capital type was 0.90 and 0.91 , respectively. The mean inter-coder reliability score for the structural features and amount of audience reactions was 0.99 .

\section{Results}

The following results are based on our analysis of 163 wall posts and 5,952 comments posted on the TOMS Facebook page and 91 wall posts and 1,618 comments posted on the Sperry Top-Sider (Sperry) Facebook page during the period of October 1, 2013 to September 30, 2014. We report first on how the two Facebook pages differ in terms of wall post topic and brand community type (RQ1) and then discuss social capital types generated through the Facebook pages (RQ2). Finally, we identify characteristics of Facebook posts that generated most audience reactions (RQ3).

Wall Post Topic and Brand Community Type (RQ1). Our research found a statistically significant difference between the TOMS Facebook page and the Sperry Facebook page in terms of the most prominent topic of each wall post analyzed $\left(\chi^{2}(1, d f=4)=15.93, p<0.01\right)$. As shown in Table 1 , a significantly higher proportion of the Facebook wall posts by Sperry focused on product promotion $(74.7 \%)$, compared with those by TOMS (54\%). Proportions of wall posts for event promotion were similar between the two with $22.1 \%$ of the TOMS wall posts and $19.8 \%$ of the Sperry wall posts focusing on promoting events related to the respective company. A significant difference between the two Facebook pages was identified with regard to how many of the wall posts emphasized social issues. A significantly higher proportion of the TOMS wall posts $(17.2 \%)$ focused on promoting a social cause or addressing a social issue, compared with the Sperry wall posts $(4.4 \%)$. During the analysis period, the TOMS Facebook page shared news and information about its One Day Without Shoes campaign, an annual international campaign aimed at raising awareness of challenges facing people in developing countries without proper footwear. Both the TOMS Facebook page and the Sperry Facebook page featured posts or images related to the ALS Ice Bucket Challenge, a non-profit fundraising campaign for addressing amyotrophic lateral sclerosis that went viral in August 2014. In 
addition, about $2.5 \%$ of the TOMS wall posts covered customer service aspects, whereas none of the Sperry wall posts analyzed focused on that topic. The difference between the two Facebook pages in terms of posts on social issues shows that TOMS utilizes its Facebook page to highlight social entrepreneurship aspects of the company and how it is helping people in developing countries. However, the fact that more than half of the wall posts on both Facebook pages focused on product promotion suggests that regardless of the difference in mission, companies are using social media sites mainly to sell their products.

Table 1. Wall Post Topic

\begin{tabular}{|l|c|c|c|c|}
\hline & \multicolumn{2}{|c|}{ TOMS } & \multicolumn{2}{c|}{ Sperry Top-Sider } \\
\hline Wall Post Topic & Count & Percent & Count & Percent \\
\hline Product promotion & 88 & $54.0 \%$ & 68 & $74.7 \%$ \\
\hline Event promotion & 36 & $22.1 \%$ & 18 & $19.8 \%$ \\
\hline Customer service & 4 & $2.5 \%$ & 0 & $0.0 \%$ \\
\hline Social issue & 28 & $17.2 \%$ & 4 & $4.4 \%$ \\
\hline Other & 7 & $4.3 \%$ & 1 & $1.1 \%$ \\
\hline Total & 163 & $100 \%$ & 91 & $100 \%$ \\
\hline
\end{tabular}

Note: $\chi^{2}(1, d f=4)=15.93, p<0.01$.

There was also an interesting difference between the TOMS Facebook page and the Sperry Facebook page in terms of brand community type featured on their wall posts $\left(\chi^{2}(1, d f=5)=90.33, p<0.001\right)$. As shown in Table 2, an overwhelming majority $(87.9 \%)$ of the wall posts on the Sperry Facebook page focused on impressions management, whereas only $29.4 \%$ of those on the TOMS Facebook page emphasized that aspect. A significantly higher proportion of the TOMS wall posts focused on community engagement (24.5\%), compared with the Sperry wall posts $(3.3 \%)$. The TOMS Facebook page also emphasized shared consciousness $(15.3 \%)$ to nurture a sense of TOMS family, while it was the most prominent aspect only in $6.6 \%$ of the Sperry wall posts.

Table 2. Brand Community Type

\begin{tabular}{|l|c|c|c|c|}
\hline & \multicolumn{2}{|c|}{ TOMS } & \multicolumn{2}{c|}{ Sperry Top-Sider } \\
\hline Brand Community Type & Count & Percent & Count & Percent \\
\hline Shared consciousness & 25 & $15.3 \%$ & 6 & $6.6 \%$ \\
\hline Impressions management & 48 & $29.4 \%$ & 80 & $87.9 \%$ \\
\hline Community engagement & 40 & $24.5 \%$ & 3 & $3.3 \%$ \\
\hline Other & 0 & $0.0 \%$ & 2 & $2.2 \%$ \\
\hline None & 50 & $30.7 \%$ & 0 & $0.0 \%$ \\
\hline Total & 163 & $100 \%$ & 91 & $100 \%$ \\
\hline
\end{tabular}

Note: $\chi^{2}(1, d f=5)=90.33, p<0.001$.

Social Capital Type (RQ2). When it comes to types of social capital (Table $3)$, the TOMS Facebook page was more likely to generate bridging social capital $(18.4 \%)$ than the Sperry Facebook page was $(1.1 \%)$. The proportion of interactions that led to bonding social capital was $63.2 \%$ for the TOMS Facebook page and $98.8 \%$ for the Sperry Facebook page. These differences were statistically significant $\left(\chi^{2}(1, d f=2)=40.88, p<0.001\right)$. 
Table 3. Bonding vs. Bridging Social Capital Type

\begin{tabular}{|l|c|c|c|c|}
\hline & \multicolumn{2}{|c|}{ TOMS } & \multicolumn{2}{c|}{ Sperry Top-Sider } \\
\hline Bonding vs. Bridging & Count & Percent & Count & Percent \\
\hline Bonding & 103 & $63.2 \%$ & 90 & $98.9 \%$ \\
\hline Bridging & 30 & $18.4 \%$ & 1 & $1.1 \%$ \\
\hline None & 30 & $18.4 \%$ & 0 & $0.0 \%$ \\
\hline Total & 163 & $100 \%$ & 91 & $100 \%$ \\
\hline
\end{tabular}

Note: $\chi^{2}(1, d f=2)=40.88, p<0.001$.

In terms of resource mobilization on Facebook (Table 4), there was also an interesting and statistically significant difference in wall posts and comments between the two companies' Facebook pages $\left(\chi^{2}(1, d f=5)=64.10, p<0.001\right)$. Recommendations and social connections were most frequently featured on both the TOMS Facebook page (50.3\%) and the Sperry Facebook page (47.3\%). However, a significantly higher proportion of interactions on the Sperry Facebook page $(26.4 \%)$ were about social coordination, invitation, or offer, compared with interactions on the TOMS Facebook page (10.4\%). Asking for favor was more prominent on the TOMS Facebook page $(9.8 \%$ ) than on the Sperry Facebook page (1.1\%). Finally, about $8.0 \%$ and $5.5 \%$ of interactions on the TOMS Facebook page and the Sperry Facebook page, respectively, were about opinion or poll.

Table 4. Resource Mobilization Social Capital Type

\begin{tabular}{|l|c|c|c|c|}
\hline & \multicolumn{2}{|c|}{ TOMS } & \multicolumn{2}{c|}{ Sperry Top-Sider } \\
\hline Resource Mobilization Type & Count & Percent & Count & Percent \\
\hline Recommendations and social connections & 82 & $50.3 \%$ & 43 & $47.3 \%$ \\
\hline Social coordination, invitation, and offer & 17 & $10.4 \%$ & 24 & $26.4 \%$ \\
\hline Favor and request & 16 & $9.8 \%$ & 1 & $1.1 \%$ \\
\hline Opinion/poll & 13 & $8.0 \%$ & 5 & $5.5 \%$ \\
\hline Other & 1 & $0.6 \%$ & 18 & $19.8 \%$ \\
\hline None & 34 & $20.9 \%$ & 0 & $0.0 \%$ \\
\hline Total & 163 & $100 \%$ & 91 & $100 \%$ \\
\hline
\end{tabular}

Note: $\chi^{2}(1, d f=5)=64.10, p<0.001$.

We also analyzed whether there is a significant association between wall post type and type of social capital generated. For this, we analyzed the TOMS wall posts and the Sperry wall posts separately to better identify patterns in each case. We found an interesting association between wall post topic and bonding vs. bridging social capital type on the TOMS Facebook page $\left(\chi^{2}(1, d f=8)=21.89, p\right.$ $<0.01)$. Wall posts about customer service generated a significantly higher proportion $(75 \%)$ of bonding social capital compared with those about product promotion $(65.9 \%)$, social issue $(64.3 \%)$, or event promotion $(52.8 \%)$. Wall posts about product promotion $(25.0 \%)$ and social issue promotion $(14.3 \%)$ were more likely to generate bridging social capital compared with the other wall post topics. There was no statistically significant association between wall post topic and bonding vs. bridging social capital type on the Sperry Facebook page. This probably is because the overwhelming majority of interactions on the Sperry Facebook page were about bonding social capital. 
An interesting association was also found between wall post topic and resource mobilization type on the TOMS Facebook page $\left(\chi^{2}(1, d f=20)=36.32, p\right.$ $<0.05)$. Wall posts focusing on both product promotion $(64.8 \%)$ and social issues (35.7\%) mostly involved resource mobilization entailing recommendations and social connections. In comparison, wall posts about both social issues $(17.9 \%)$ and event promotion $(16.7 \%)$ were most likely to generate interactions regarding social coordination, invitation, and offer. In comparison, wall posts on product promotion $(63.2 \%)$ was most likely to generate resource mobilization in the form of recommendations and social connections, whereas those on event promotion $(77.8 \%)$ led to resource mobilization in the form of social coordination, invitation, and offer.

Audience Reactions (RQ3). On average, wall posts on the TOMS Facebook page received more audience reactions - numbers of likes, comments, and shares - than those on the Sperry Facebook page. For example, the TOMS Facebook wall posts received an average of more than 1,500 likes $(M=1,574.06$, $S D=4,830.03)$, whereas the Sperry wall posts received just over 900 likes on average $(M=937.03, S D=1,029.75)$. On average, about 36 comments $(M=$ $36.51, S D=198.70)$ were generated to each Facebook wall post on the TOMS Facebook page and about 17 comments on the Sperry Facebook page $(M=17.78$, $S D=23.63$ ). However, the differences were not statistically significant based on analysis of variance (ANOVA) tests. It is interesting that there is no statistically significant difference between the two in terms of audience reactions despite the fact that the TOMS Facebook has a significantly higher number of fans (about 2.8 million as of October 2014) than the Sperry Facebook page (about one million as of October 2014).

Wall posts on the TOMS Facebook page received different amounts of audience reactions depending on brand community types indicated through those wall posts. Wall posts featuring shared consciousness received most Facebook likes $(M=1,055.40, S D=1,464.14)$, followed by impressions management $(M=$ 7.17.93, $S D=903.69)$ and community engagement $(M=520.72, S D=861.16)$. The difference was statistically significant according to an ANOVA test $(F=4.09$, $p<0.01)$. In comparison, wall posts about community engagement $(M=33.75$, $S D=133.82)$ received most comments, followed by shared consciousness $(M=$ $10.60, S D=18.54)$ and impressions management $(M=7.52, S D=9.05)$. However, the differences on the amounts of comments were not statistically significant $(F=1.27, p=$ n.s. $)$.

On the Sperry Facebook page, wall posts supporting the brand community type of shared consciousness received most likes $(M=1,109.83, S D=716.38)$, followed by impressions management $(M=959.70, S D=1072.20)$, and community engagement $(M=312.00, S D=301.42)$. However, the differences were not statistically significant $(F=0.57, p=$ n.s. $)$. Similar patterns were identified with regard to numbers of comments and shares.

When it comes to wall post topic and audience reactions, wall posts about product promotion received most likes $(M=2,443.75, S D=6,313.89)$ on the TOMS Facebook page, followed by other $(M=864.28, S D=494.92)$, event promotion $(M=581.63, S D=1,149.84)$, social issue $(M=488.64, S D=488.25)$, 
and customer service $(M=210.50, S D=242.95)$. The pattern was similar for the number of comments. Wall posts about product promotion received most comments $(M=57.19, S D=266.74)$, followed by event promotion $(M=19.44$, $S D=58.15)$, social issue $(M=6.85, S D=8.94)$, other $(M=3.00, S D=1.82)$, and customer service $(M=1.50, S D=1.73)$. However, the differences were not statistically significant (likes: $F=1.58, p=$ n.s.; comments: $F=0.53, p=$ n.s.). Similar patterns were found on the Sperry Facebook page.

\section{Discussion}

Social media has significantly influenced the ways organizations engage their publics by facilitating direct interactions between an organization and its publics without involvement of traditional intermediaries such as mass media. These direct interactions provide opportunities for generating social capital that can have positive impacts on society. In this study, we analyzed whether and how a for-profit social enterprise (TOMS) differs from a conventional forprofit company (Sperry Top-Sider) in terms of using social media for building and maintain relationships with publics and of generating social capital via its brand community online. Several interesting and important findings emerged through our research.

First of all, interactions on the TOMS Facebook page were more likely to generate bridging social capital, compared to those on the Sperry Facebook page. Bridging social capital, which is typically generated from weak or peripheral social connections, is essential for exposing people to novel information and new perspectives (Ansari et al., 2012; Burt, 2001; Lin, 2001; Putnam, 2000; Williams, 2006). The presence of bridging social capital on the TOMS Facebook page was particularly prominent during the company's One Day Without Shoes campaign in April 2014. During this annual global campaign aimed at raising awareness for children's health and education, TOMS asked people to spend the annual day without shoes and experience what it is like not having proper footwear (TOMS, 2014). People around the world shared photos of themselves going barefoot and also posted information about how the campaign was implemented in different countries. Facebook users showed their support for the campaign by "liking" those photos. Indeed, photos related to this campaign received the most audience reactions. TOMS also featured news and images about local communities around the world, which led to further new information from its Facebook fans. For example, in response to TOMS's wall post on children in Africa, a Facebook user commented that: "While I was in Sierra Leone some of my friends and students at my school had TOMS shoes!" This is in line with our finding that wall posts related to social issues were more likely to generate bridging social capital. These results suggest that the social entrepreneurship aspect of TOMS contributes to information exchanges between weak ties and forging of new ties via its brand community on Facebook.

While bridging social capital was more prominent on the TOMS Facebook page than on the Sperry Facebook page, it should be noted that bonding social 
capital was more prevalent in both Facebook pages. Bonding social capital generally stems from close social connections that are likely to share norms and trust (Ansari et al., 2012; Burt, 2001; Lin, 2001; Putnam, 2000; Williams, 2006). The prevalence of bonding social capital on both Facebook pages makes sense since those who visit and engage with the Facebook page are more likely to be the respective company's fans and thus may share a sense of community or family. Our analysis of the association between wall post topic and bonding vs. bridging social capital type shows that wall posts about customer service and product promotion was more likely to generate bonding social capital. For example, when TOMS and Sperry feature their new products on their Facebook page, people often tagged some Facebook user names, which indicates that they want their Facebook friends to pay attention to these new products. Similar interactions between close friends were also found on some wall posts related to customer service. The TOMS Facebook page featured the following on May 21, 2014: "Hey everyone! Just want to say sorry for the returns issue some people are experiencing on our US site. We're aware and are working to fix as soon as possible. Thank you so much for your patience!" This post generated lengthy exchanges between TOMS and customers and among customers. Some of the comments indicated information exchanges between close friends.

Our results suggest that the TOMS Facebook page is more involved in community engagement aspect of brand community than the Sperry Facebook page is. In the context of brand community online, community engagement refers to a set of practices where customers are encouraged to share their experiences and stories related to the brand (Habibi et al., 2014). Of the specific practices of community engagement identified in Habibi et al.'s (2014) study, "milestoning" and "documenting" were present on the TOMS Facebook page. Milestoning refers to "customers' experiences on specific occasions with their brand" (Habibi et al., 2014, p. 128). TOMS asked people to share their images participating in the One Day Without Shoes campaign, and some customers mentioned that it was their first time to participate in the campaign. Documenting was created on the TOMS Facebook page "whenever customers shared their experiences and stories with the brand" (Habibi et al., 2014, p. 128).

Despite these differences, both companies use their Facebook page primarily to sell their products. Our analysis shows that more than half of the wall posts on each Facebook page featured product promotion. While the proportion of wall posts related to product promotion was significantly higher on the Sperry Facebook page than on the TOMS Facebook page, the still high visibility of product promotion on the TOMS Facebook page calls for a discussion on the use of social media by for-profit social enterprises. TOMS, which donates a pair of shoes for every pair sold, has been considered as one of the leading examples of social entrepreneurship using business models to address social problems (Skoll World Forum, 2013). Yet, our analysis shows that less than $20 \%$ of wall posts on the TOMS Facebook page directly address social issues. A majority of TOMS Facebook wall posts focus on promoting the company's new products without ever mentioning social impact aspects of consumer purchase of the products. For example, during our analysis period, 
there were numerous posts such as this: "Summer has been incredible. Keep the excitement going this fall in printed and patterned back to school styles." TOMS' Facebook wall posts dealing with social issues were mainly posted during the company's One Day Without Shoes campaign. For example, TOMS posted the following on its Facebook on April 10, 2014: "Podoconiosis is not only treatable, but it is also 100 percent preventable - just by wearing shoes. Help raise awareness and join the \#TOMS family by going without shoes on April 29." This finding indicates that for-profit social enterprises like TOMS may be missing important opportunities for utilizing their brand communities online to raise awareness of the social issues that they focus on and for encouraging relevant action on the part of the citizens. This is an important matter to consider, given the potential of social entrepreneurship for creating value-embedded social relationships (Gedajlovic et al, 2013).

Contributions. This research enhances our understanding of differences and similarities between for-profit social enterprises and conventional for-profit companies in use of social media for public relations and their implications for generating relevant social capital. Our study also updates literature on social capital in the age of online social networking by showing how different types of social capital might be created via brand communities online. In addition, theoretical and methodological approaches developed in this study help advance research on the role of social media-facilitated public relations for addressing social problems at the local, national, or international level.

Limitations and Future Research. As is the case with any empirical research, our study is not without limitations. In this research we focused on textual wall posts and corresponding comments, and did not analyze images posted on the TOMS and Sperry Facebook pages. We made the decision to focus on textual wall posts and comments in this study because our research questions were about wall post type, brand community type, and social capital type. However, it would be useful to analyze images accompanying those wall posts in future research.

In addition, there are some potential confounding factors that may have influenced the amount of audience reactions on the TOMS and Sperry Facebook pages. For example, some of the wall posts may have received a high level of audience reactions because they were shared by social media influencers-those who have a lot of followers on their social media sites and those whose connections have a lot of followers. It is also possible that some comments on the original wall post may have contributed to generating more comments from Facebook users. While we analyzed both topic and valence of comments, we did not analyze the relationships between comments. It should be also noted that companies can delete negative comments on their Facebook page.

Future research may examine online brand communities of multiple for-profit social enterprises to identify patterns of social media use and social capital creation in those communities. It would be also useful to compare Facebook pages of TOMS in different countries. TOMS has several Facebook pages in different countries including Japan, South Korea, and Taiwan. It will be interesting to see how online communities of the same brand emphasize different topics or brand community aspects and thus generate different types of social capital. 


\section{References}

Anderson, M., \& Caumont, A. (2014). How social media is reshaping news. Pew Research Center. Retrieved from goo.gl/SizaEM.

Aubrey, J. S., \& Rill, L. (2013). Investigating Relations Between Facebook Use and Social Capital Among College Undergraduates. Communication Quarterly, 61(4), 479-496.

Ansari, S., Munir, K., \& Gregg, T. (2012). Impact at the "bottom of the pyramid": the role of social capital in capability development and community empowerment. Journal of Management Studies, 49(4), 813-842.

Benkler, Y. (2006). The wealth of networks: how social production transforms markets and freedom. New Heaven and London: Yale University Press.

Bourdieu, P. (1986). The forms of capital. In J. G. Richardson (Eds.,), Handbook of theory and research for the sociology of education (pp. 214-258). New York: Greenwood.

Burt, R. (2001). Structure holes versus network closure as social capital. In N. Lin, K. Cook, \& R. Burt (Eds.), Social capital: Theory and research (pp. 31-56). New York: Aldine de Gruyter.

Coleman, J. S. (1988). Social capital in the creation of human capital. The American Journal of Sociology, 94, 95-120.

Doerfel, M. L., \& Haseki, M. (2013). Networks, disrupted: Media use as an organizing mechanism for rebuilding. New Media \& Society, 17(3), 432-452.

Ellett, J. (2014, August 19). How TOMS creates customers for life. Forbes. Retrieved from goo.gl/vgLwea.

Ellison, N., Gray, R., Vitak, J., Lampe, C., \& Fiore, A. (2013). Calling All Facebook Friends: Exploring requests for help on Facebook. In Proceedings of the 7th Annual International Conference on Weblogs and Social Media (pp. 155-164). Washington, DC: Association for the Advancement of Artificial Intelligence.

Ellison, N. B., Vitak, J., Gray, R., \& Lampe, C. (2014). Cultivating social resources on social network sites: Facebook relationship maintenance behaviors and their role in social capital processes. Journal of Computer-Mediated Communication, 19(4), 855-870.

Gedajlovic, E., Honig, B., Moore, C. B., Payne, G. T., \& Wright, M. (2013). Social capital and entrepreneurship: A schema and research agenda. Entrepreneurship Theory and Practice, 30(1), 455-478.

Gil de Zúñiga, H., Jung, N., \& Valenzuela, S. (2012). Social media use for news and individuals' social capital, civic engagement and political participation. Journal of Computer-Mediated Communication, 17(3), 319-336.

Habibi, M. R., Laroche, M., \& Richard, M. O. (2014). Brand communities based in social media: How unique are they? Evidence from two exemplary brand communities. International Journal of Information Management, 34(2), 123-132.

Heath, R. L. (2006). Onward into more fog: Thoughts on public relations' research directions. Journal of Public Relations Research, 18, 93-114.

Johnson, T. J., Zhang, W., Bichard, S., \& Seltzer, T. (2010). United we stand?: Online social network cites and civic engagement. In Z. Papacharissi (Eds.), The networked self: Identity, community, and culture on social network sites (pp. 185207). New York: Routledge.

Kelleher, T., \& Miller, B. M. (2006). Organizational blogs and the human voice: Relational strategies and relational outcomes. Journal of Computer-Mediated Communication, 11, 395-414. 
Kennan, W. R., Hazelton, V. (2006). Internal public relations, social capital, and the role of effective organizational communication. In C. H. Botan \& V. Hazelton (Eds.), Public relations theory II (pp. 311-338). Mahwah, NJ: Lawrence Erlbaum.

Ki, E.-J., \& Hon, L. C. (2006). Relationship maintenance strategies on Fortune 500 company websites. Journal of Communication Management, 10, 27-43.

Krippendorff, K. (2013). Content analysis: An introduction to its methodology. London, U.K.: Sage Publications.

Kruckeberg, D., \& Stark, K. (1998). Public relations and community: A reconstructed theory. New York, NY: Praeger.

Lampe, C., Ellison, N., Steinfield, C. (2006). A face(book) in the crowd: Social searching vs. social browsing. Proceedings of CSCW 2006, Banff, Alberta, Canada.

Leeper, K. (2000). In search of a meta theory of public relations: An argument for communitarianism. In R. L. Heath (Eds.), Handbook of public relations (pp. 93104). Thousand Oaks, CA: Sage Publications.

Lin, N. (2001). Social capital: A theory of social structure and action. Cambridge: Cambridge University Press.

Mano, R. S. (2014). Social media, social causes, giving behavior and money contributions. Computers in Human Behavior, 31, 287-293.

Mikami, K. (2014). An alternative framework for the analysis of social enterprises. Journal of Co-operative Organization and Management, 2, 92-97.

Mintel. (2014a). Men's and Women's Footwear - US - September 2014. Retrieved from Mintel Academic database.

Mintel. (2014b). Marketing to Millennials - US - February 2014. Retrieved from Mintel Academic database.

Morris, M. R., Teevan, J., \& Panovich, K. (2010). A comparison of information seeking using search engines and social networks. In Proceedings of the Fourth International AAAI Conference on weblogs and Social Media (pp. 291-294). New York: ACM.

Muniz, A. M., \& O'Guinn, T. C. (2001). Brand community. Journal of Consumer Research, 27(4), 412-432.

Pew Research Center. (2015). Social media update 2014. Retrieved from goo.gl/LOPiH3.

Poulos, J. (2012, April 11). TOMS shoes: A doomed vanity project? Forbes. Retrieved from goo.gl/ieM7Dk.

Putnam, R. (2000). Bowling alone: The collapse and revival of American community. New York: Simon \& Schuster.

Riffe, D., Lacy, S. \& Fico, F. (2005). Analyzing media messages: Using quantitative content analysis in research. Mahwah, NJ: Lawrence Erlbaum Associates.

Ross, M. (2014, February 3). Facebook turns 10: The world's largest social network in numbers. ABC News. Retrieved from goo.gl/OLZeBp.

Skoll World Forum. (2013, May 2). The rise of social entrepreneurship suggests a possible future for global capitalism. Forbes. Retrieved from goo.gl/gg6D8.

Somaiya, R. (2014, October 26). How Facebook is changing the way its users consume journalism. The New York Times. Retrieved from goo.gl/N7B2x.

Sommerfeldt, E. J., \& Taylor, M. (2011). A social capital approach to improving public relations' efficacy: Diagnosing internal constraints on external communication. Public Relations Review, 37, 197-206.

Sperry Top-Sider. (2014). "Our Story." Sperry Top-Sider. Retrieved from goo.gl/3 TcqqO. 
Strom, S. (2014, March 11). Turning coffee into water to expand business model. The New York Times. Retrieved from goo.gl/1Wybxb.

Taylor, M. (2011). Building social capital through rhetoric and public relations. Management Communication Quarterly, 25(3), 436-454.

Teasdale, S., Lyon, F. \& Baldock, R. (2013). Playing with numbers: A methodological critique of the social enterprise growth myth. Journal of Social Entrepreneurship, 4(2), 113-131.

TOMS. (2014). One Day Without Shoes. Retrieved from goo.gl/5d3WvC.

Trumbull, M. (2014, June 1). Growth sector: "Social entrepreneurship" is trending. Christian Science Monitor. Retrieved from goo.gl/ZaMxp3.

Twitter. (2014). About Company. https://about.twitter.com/company

Williams, D. (2006). On and off the "net": Scales for social capital in an online era. Journal of Computer-Mediated Communication, 11, 593-628.

Wydick, B., Katz, E., \& Janet, B. (2014). Do in-kind transfers damage local markets? The case of TOMS shoe donations in El Salvador. Journal of Development Effectiveness, 6(3), 249-267.

Zarhana, R. S., Arsenault, A., \& Fisher, A. (Eds.). (2013). Relational, networked, and collaborative approaches to public diplomacy: The connective mindshift. New York: Routledge.

Zhang, W., Johnson, T. J., Seltzer, T., \& Bichard, S. (2010). The revolution will be networked: The influence of social networking sites on political attitudes and behavior. Social Science Computer Review, 28, 75-92. 